\title{
Heat Operated Refrigeration Systems
}

\author{
Pramod S. Gunjarge* and Harish U. Tiwari \\ Department of Mechanical Engineering, Savitribai Phule Pune University, Maharashtra, India \\ Accepted 15 June 2016, Available online 20 June 2016, Special Issue-5 (June 2016)
}

\begin{abstract}
Energy consumption in buildings has been increased due to HVAC systems in recent years with the development of the economy worldwide Air-conditioning is provided by electrically-driven vapor-compression air conditioning unit especially during the summer. Electrically driven VCR requires high grade energy and it also damage our environment. On other hand thermally driven adsorption refrigeration and absorption refrigeration systems got considerable attention nowadays not due to its manufacturing simplicity, but also having environment friendly adsorbent/refrigerant pairs. The present work is focused towards the development of a prototype of vapour adsorption refrigeration system and design of the innovative vapor absorption system using aqua ammonia and a prototype of $1 \mathrm{KW}$ capacity has been designed, developed and tested in the laboratory for vapour adsorption as well as absorption systems. In the present work the heating time required to achieve the cooling effect is around 10 minutes. The COP of the system is in the range of 0.08 to 0.190 . The major problem in absorption system is that, along with the ammonia, water also enters into the condenser and the evaporator tube which hampers the cooling effect.
\end{abstract}

\section{Keywords: Absorption, Adsorption, Ammonia-water}

\section{Introduction}

In the heat operated refrigeration system heat is used as an energy source to compress the refrigerant like the compressor is use of electrically driven vapor compression system. In the current study adsorption and absorption refrigeration systems are tested for space cooling. In the adsorption refrigeration system, there is two linked vessels, one of which contains the adsorbent-refrigerant pair called generator and the second which contains only refrigerant called evaporator-condenser. Vessels are initially at low pressure and temperature. The first step consists of heating the generator due to this refrigerant gas is driven out from the adsorbent and the pressure of the system increases. This high pressure refrigerant gas is condensed in the evaporator-condenser. When the deception process is completed, then the generator is started calling to initial temperature due to this starts adsorbing the refrigerant, this adsorbing process, reducing the pressure in the evaporator, condenser causes the boiling of refrigerant, absorbing heat and therefore producing the necessary cooling effect.

Habib et al. With $70^{\circ} \mathrm{C}$ energy source for combined adsorption system in which a heat exchanger is used as an evaporator and condenser at the same time. With working pair R134a and activated carbon and activated carbon adsorbent R507a, for high cycle and low cycle,

${ }^{*}$ Corresponding author: Pramod S. Gunjarge
$85 \mathrm{~kW}$ cooling capacity is achieved by them with $10^{\circ} \mathrm{C}$ chilled water outlet temperature, and coefficient of performance 0.069 is calculated.

Tamainot-Telto et al. After investigating the 26 carbon ammonia pair for a testing adsorbing capacity of activated carbon in single bed, two-bed adsorption refrigeration system. With the temperature sources varied from $80^{\circ} \mathrm{C}$ to $200^{\circ} \mathrm{C}$. They found coconut shell carbon is best suitable working pair with ammonia in adsorption system. The carbon adsorbents investigated are coconut shell and coal based type's carbons.

W.S. Chang et al. with silica gel as the adsorbent and water as the absorbent. Within the temperate range of $80^{\circ} \mathrm{C}$ hot water and $30^{\circ} \mathrm{C}$ cooling water the absorption system is manufactured with simplicity and at low cost. Where a vacuum tank is designed in such a manner that it contain adsorption bed. And they use flat-tube type heat exchanger to improve heat transfer rate by experiment they achieve 4.3KW cooling and cop 0.45 .

$\mathrm{Xu}$ Ji et al. In this paper $\mathrm{LiBr}-\mathrm{H}_{2} \mathrm{O}$ pair is used as working pair. Here the need of a rectifier is eliminated and extremely high heat of vaporization of water as refrigerant. However, using water as a refrigerant limits lower temperature application to that below $0^{\circ} \mathrm{C}$. As water is the refrigerant, the system must be operated under vacuum conditions. It is also corrosive to some metal and expensive.

H.U. Tiwari et al. Presented design, development and experimentation of an adsorption refrigeration system powered by exhaust heat with only two control 
valves. The truck cabin cooling load is calculated as 1TR and a scale of 3.5:1 is taken to design prototype for the experiment in the current paper by scaling $1 \mathrm{KW}$ system is a design developed and tested in the laboratory. For $1 \mathrm{KW}$ capacity system weight is $30 \mathrm{~kg}$ and cop in the range of 0.4 to 0.45 . The heating time required to achieve the cooling effect is around 10 minutes.

M. S. ahmed et al. In this paper the survey of absorbing fluids is done. They survey 40 refrigerant and 200 absorbent compounds. They find Water $/ \mathrm{NH}_{3}$ and $\mathrm{LiBr} /$ water are most suitable and commonly use working poor.

\section{Experimental Details}

With the proposed system necessary heat to the absorber is supplied by using hot circulating water. The schematic diagram of the system is shown in Figure 1. This is an absorption refrigeration system with a single control valve. This system requires only one coil connected to the absorber through the control valve. The coil connected to the absorber through a control valve acts as a condenser as well as an evaporator. The absorber-generator unit is actually a pipe in pipe type of heat exchanger. Two concentric pipes are used such that the hot water passes through the gap between outer and inner pipe and inner pipe is filled with the liquid ammonia. The absorber is heated by circulating hot water and refrigerant is absorbed and condensed in the coil at high pressure, here the coil acts as a condenser and is filled with liquid refrigerant. The control valve is closed and the absorber is cooled. The pressure in the absorber reduces and the absorber regains its absorptivity. The control valve gradually opened and the liquid refrigerant evaporates and flows back to the absorber, where the absorber absorbs the refrigerant. The coil this time act as evaporator and refrigerating effect is generated at the evaporator coil. The pressure of the refrigerant in the absorber gradually increases.

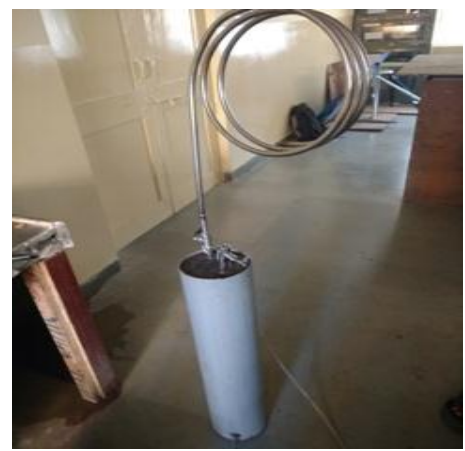

Fig.1: Absorption refrigeration Experimental Setup

\section{Design of Proposed System}

The main system components are Absorber-generator unit, condenser \& evaporator coil and control valve. By using heat transfer equation and thermal correlation heat exchangers are designed. In the laboratory first develop a prototype to study the effect of different variables. A prototype of $1 \mathrm{~kW}$ capacity is designed and developed in the Laboratory. The absorber and refrigerant are selected as water and Ammonia. Considering the high latent heat of Ammonia and solubility of ammonia in the water this combination is found to be suitable. The absorber, condenser, evaporator and the control valves are the main components of the system. The absorber has been designed and developed to enhance the heat transfer.

\subsection{Design of Absorber-Generator Unit}

In absorption refrigeration system, absorber is the most important component Absorber works like generator as well as absorber both of an absorption system. It is double pipe heat exchanger. There are two concentric tubes in which inner is stainless steel and outer is PVC. The absorbing water is filled between the gaps of inner tube. The absorbing material is water and the refrigerant is ammonia. The gap between inner and outer tube is used for circulating hot water for heating. End covers are fitted at the ends of these tubes to hold the absorbing material. The system is designed for heating and cooling time of 600s. Absorber temperatures are decided as $\mathrm{Tab}_{\max }=80^{\circ} \mathrm{C}$ and $\mathrm{Tab}_{\min }$ $=30{ }^{\circ} \mathrm{C}$. Designed refrigerating effect (R.E.) $=1 \mathrm{~kW}$, latent heat of evaporation of ammonia (L) at evaporator pressure is $1250 \mathrm{~kJ} / \mathrm{kg}$. Amount of ammonia is obtained by dividing the R.E. by latent heat as $0.48 \mathrm{~kg}$. Mass of absorber $\left(\mathrm{m}_{\mathrm{ab}}\right)$ is obtained as 1.40 $\mathrm{kg}$. Density of absorbing material is $1000 \mathrm{~kg} / \mathrm{m}^{3}$

\subsubsection{Mass of absorber and refrigerant}

\section{Refrigerant- Ammonia}

Absorbent- Water

Concentration of ammonia in water.

$\mathrm{X}_{\text {max }}=$ Concentration at $30^{\circ} \mathrm{C}$

$\mathrm{X}_{\min }=$ Concentration at $80^{\circ} \mathrm{C}$

Mass of refrigerant $=(\mathrm{R} . \mathrm{E} \div \mathrm{L}) \times \Delta \mathrm{t}$

Mass of absorber $\left(\dot{\mathrm{m}}_{\mathrm{ab}}\right)=\mathrm{m}_{\mathrm{r}} \div\left(\mathrm{X}_{1}-\mathrm{X}_{2}\right)$

\subsubsection{Selection of inner tube and outer tube}

The inner tube and outer of the absorber-generator unit is selected based on the heating method and available raw material. The inner tube contain liquid ammonia 4litters, even capacity of tube is 6litters last two litters are remains unfilled, that space is allow to condense steam which is coming out with ammonia during the heating. Gap between outer and inner pipe is used to circulate hot and cold water as per the cycle time 600s. Using water for heating absorber gives 
uniform heating and reduce the steam contain in Where, ammonia vapour.

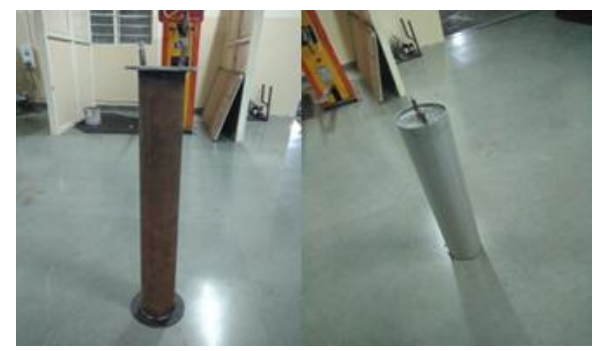

Fig. 2. Tube and outer tube

Table 1 Dimensions of Absorption Bed

\begin{tabular}{|c|c|}
\hline Components & Dimensions \\
\hline Outer pipe & $\mathrm{D}_{\mathrm{i}}=105 \mathrm{~mm}$, \\
\hline Inner pipe & $\mathrm{D}_{\mathrm{i}}=140 \mathrm{~mm}$, \\
\hline length & $700 \mathrm{~mm}$, \\
\hline capacity & 6 litters. \\
\hline
\end{tabular}

\subsection{Design of condenser and evaporator coil}

In presented vapour absorption refrigeration system same coil is used as the condenser \& Evaporator both. The coil is designed based on the amount of heat to be rejected to the cooling water. The rise in temperature of the cooling water is assumed as $10^{\circ} \mathrm{C}$. The condenser coil is connected to the Absorber-Generator unit through the control Valve.

1. Enthalpy of refrigeration Consider enthalpy at given temperature and pressure and values are taken.

2. Mass of refrigerant,

$$
\dot{\mathrm{m}}_{\mathrm{r}}=(\text { R.E. } \div \text { Latent heat })
$$

3. The amount of heat to be rejected in the condenser

$$
\mathrm{Q}_{\text {condenser }}=\dot{\mathrm{m}}_{\mathrm{r}}\left(\mathrm{H}_{2}-\mathrm{H}_{1}\right)
$$

4. The log mean temperature difference is given by,

$$
L M T D=\frac{\theta_{1}-\theta_{2}}{\ln \frac{\theta_{1}}{\theta_{2}}}
$$

5. The area of the condenser coil to reject the calculated

$$
\mathrm{Q}_{\text {condenser }}=\mathrm{U} \cdot \mathrm{A} \cdot(\Delta \mathrm{T}) \mathrm{LMTD}
$$

Consider the diameter of the coil. Hence the length of the coil is calculated as,

\subsection{COP of the system}

$$
\mathrm{A}=\Pi \mathrm{D}_{1} \mathrm{l}
$$

Sensible and Latent heat can be given as,

$$
\begin{aligned}
& \text { Qsensible }=\left(\mathrm{m}_{\mathrm{ab}} \times \mathrm{Cp}_{\mathrm{ab}} \times \Delta \mathrm{T}_{\mathrm{ab}}\right)+\left(\mathrm{m}_{\text {tube }} \times\right. \\
& \left(\mathrm{p}_{\text {tube }} \times \Delta \mathrm{T}_{\mathrm{ab}}\right) / \Delta \mathrm{t}
\end{aligned}
$$

$$
\begin{gathered}
\text { Cp water }=4.187 \mathrm{KJ} / \mathrm{Kg} \cdot \mathrm{k} \\
\mathrm{Q}_{\text {latent }}=\left\{\mathrm{m}_{\mathrm{ab}}\left(\mathrm{X}_{2}-\mathrm{X}_{1}\right)\left(\mathrm{H}_{2}-\mathrm{H}_{1}\right)\right\} / \Delta \mathrm{t}
\end{gathered}
$$

Total heat can be given as,

$$
Q_{\text {total }}=Q_{\text {sensible }}+Q_{\text {latent }}
$$

COP of the system.

$$
\mathrm{COP}=\mathrm{Q}_{\text {evaporator }} / \mathrm{Qtotal}
$$

\subsection{Development of the prototype}

In the present paper the adsorption refrigeration prototype is also tested for space cooling.

Following are consideration for the adsorption system.

- Activated carbon and ammonia select as working pair.

- The adsorptivity of activated carbon for ammonia below $75^{\circ} \mathrm{C}$ is around $30 \%$ and that above $165^{\circ} \mathrm{C}$ is around $0 \%$.

- Hence, adsorber bed temperatures are decided as $\mathrm{T}_{\text {ad }} \max =165^{\circ} \mathrm{C}$ and $\mathrm{T}_{\text {ad }} \min =75^{\circ} \mathrm{C}$.

- The system is designed for heating and cooling time of 360 s the time required for adsorption or desorption.

- Designed refrigerating effect (R.E.) $=2 \mathrm{TR}$ at evaporator pressure of 5 bar Latent heat of evaporation of ammonia (L) is $1250 \mathrm{~kJ} / \mathrm{kg}$.

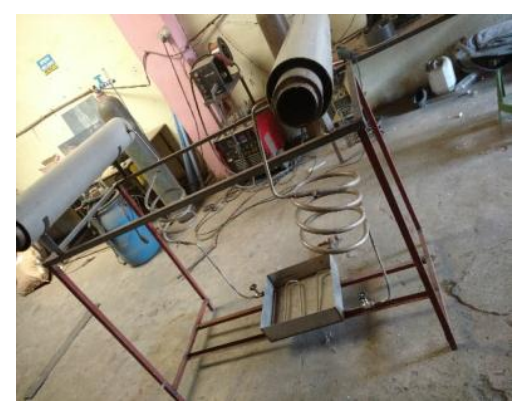

Fig.3 Actual Experimental Adsorption Refrigeration

fig.3 shows actual setup for adsorption refrigeration prototype where there is tube in tube heat exchanger is use as adsorber bed where the gap between outer and inner tube filled with activated carbon and aluminum chips, aluminum have good thermal conductivity mixture of aluminum and activated carbon is $20 \%-80 \%$ respectively which increasing the heat transfer rate. The cooling effect at evaporative coil is use for cooling water. This cool water then circulating in the space for cooling.

\subsubsection{Instrumentation}

1. 63mm Dial Pressure Gauge Bottom Entry

The pressure gauges listed below have a $63 \mathrm{~mm}$ dial and have a stainless steel bezel. 
They have a 1/4" BSP bottom entry connection and are dual scale in both PSI and bar.

- $1 / 4 "$ BSP - Bottom entry

- Dual scale - PSI \& Bar

- Accuracy: $1.6 \%$ as per UNI 8293

- Ambient temperature: $\mathrm{Max}+65^{\circ} \mathrm{C}$

- Process temperature: $\mathrm{Max}+65^{\circ} \mathrm{C}$

- Working pressure: Max 75\% of the full scale value

- Over pressure limit: (Referred to the full scale value)

- $25 \%$ for pressure ranges up to 100 bar.

- $15 \%$ for pressure ranges over 100 bar.

2. Thermocouple

- $\quad$ Type: K type Chromel (+) Yellow Alumel (-) Red.

- Temperature Range for Standard Limits of Error: ( 0 to $293^{\circ} \mathrm{C}$ )

- Standard Limits of Error: $\left( \pm 2.2^{\circ} \mathrm{C}\right)$

- Special Limits of Error: $\left( \pm 1.1^{\circ} \mathrm{C}\right)$

\subsubsection{Material Consideration for Ammonia /Water System}

Use of copper or copper-containing material is Impossible for ammonia water or any ammonia refrigeration because ammonia is a very good solvent for copper. Even chromium plated brass parts are susceptible to ammonia corrosion. with ammonia the mostly steel or stainless steel is used for preventing form the corrosion in the some application there some slat added in the small quantity only $1 \%$ by weight. This slat form oxide layer on the material surface this layer prevent direct contact of ammonia with material. The influence of these salts on the thermodynamic properties of the working fluid is usually not consider. Traditionally, the corrosion inhibitors are salts that contain heavy metals. The thermal conductivity of steel is about one tenth of that of copper.

\subsubsection{Selection of standard components}

The different standard components used are Pressure Gauge, Two end threaded collars and Two Expansion valves. The pressure gauge is selected for the range of 0-20 bar pressure as the maximum pressure in the system is 15 bar. The pressure gauge is dedicated for ammonia gas pressure measurement. The expansion valves are steel needle valves. In auxiliary devises we use blower stove to supply heat.

\section{Conclusions}

This research work proposes an innovative, compact, and improved absorption refrigeration system design, powered by waste heat. The system, which has been designed, developed and tested during the course of the presented research work, makes the following contributions in the field of absorption refrigeration technology.

1. An innovative absorption refrigeration system powered by heat has been designed, developed and tested.

2. An absorption heat exchanger, which is a vertical tube in tube type due to vertical design after heating when the water, vapour, which is coming out with ammonia is falling down into absorber generator and only dry and hot ammonia come out. No need of rectifiers to separate ammonia and steam.

3. An environment friendly cooling system has been developed that does not rely on electric power, and thus helps in reducing resulting pollution as well as global warming. The Global Warming Potential (GWP) of ammonia is zero.

4. A cooling system has been developed that does not use a CFC refrigerant, and thus protect ozone layers over the atmosphere.

5. The developed absorption system design provides a platform for further development of absorption refrigeration technology and for waste heat operated cooling systems.

\section{References}

Khairul Habib et al, (2011) Performance evaluation of combined adsorption refrigeration cycles, international journal of refrigeration, vol. 32, pp. 129137.

Y.J. He al,(2015),Theoretical analyses of a new two-stage absorptiontranscritical hybrid refrigeration system,international journal of refrigeration, vol. 56, pp. 105-113.

J. Sage-Lauck and D. Sailor,(2004)“Compound adsorbent for adsorption ice maker on fishing boats," international journal of refrigeration, vol. 27, pp 401-408.

Z. Tamainot-Telto et al,(2009) "Carbon-ammonia pairs for adsorption refrigeration applications: ice making, air conditioning and heat pumping," international journal of refrigeration, vol. 32, pp. 1212-1229.

Harish Tiwari,(2012) Dr. G. V. Parishwad, Adsorption Refrigeration System for Cabin Cooling of Trucks, International Journal of Emerging Technology and Advanced Engineering, Volume 2.

$\mathrm{Xu}$ Ji et al,(2014),Structure optimization and performance experiments of a solar-powered finned-tube adsorption refrigeration system, Applied Energy, vol. 113, pp. 1293-1300.

M. S. ahmed et al,(2014),A review: future of the adsorption working pairs in cooling, mechanical engineering department, sohag university, sohag, egypt.

Crepinsek Z et al, (2009), Comparison of the performances of absorption refrigeration cycles, University of Maribor, vol. 4.

Wang D. C. P. et al, (2014), A Review on Adsorption Refrigeration Technology and Adsorption Deterioration in Physical Adsorption Systems, Renewable And Sustainable Energy Reviews, vol. 14, pp. 344-354.

Lambert M. A. et al, (2006), Automotive adsorption air conditioner powered by exhaust heat part 1: conceptual and embodiment design, Journal of Automobile Engineering, vol. 220.

Darwish N.A, (2008), Performance analysis and evaluation of commercial absorption-refrigeration water-ammonia system, International Journal of refrigeration, pp.1214-1223.

Jose Fernandez-Seara, Manuel Vazquez, (2006), The importance of the ammonia purification process in ammonia-water absorption system, Energy conservation and management, vol. 47, pp. 1975-1987.

Alam S, (2006), A Proposed model for Utilizing Exhaust Heat to run Automobile Air-conditione, The 2nd Joint International Conference on Sustainable Energy and Environment, pp.21-23, Bangkok, Thailand.

Marcriss R.A, Gutraj J.M, Zawacki T.S, (1988), Absorption fluid data survey: final report on worldwide data, ORLN/sub/8447989/3, Inst. Gas Tech.

ParkY.M, Sonntag R.E, (2009), Thermodynamic properties of ammonia-water mixtures a generalized equation- of-state approach, ASHRAE Trans; 96:150 9.

M.A. Lambert and B.J.Jones, (2006), Automotive adsorption air conditioner powered by exhaust heat, Part 1, conceptual and embodiment design.

Crepinsek Z, D.Goricanec, J. Krope, (2009), Comparison of the performances of absorption refrigeration cycles, University of Maribor ISSN: 1790- 504465 Volume 4. 